Published in final edited form as:

Blood Purif. 2012 ; 34(2): 138-148. doi:10.1159/000342129.

\title{
Pediatric Renal Replacement Therapy in the Intensive Care Unit
}

\author{
Brian C. Bridges ${ }^{a,}{ }^{,}$, David J. Askenazi ${ }^{\mathrm{b}}$, Jessimene Smith ${ }^{\mathrm{b}}$, and Stuart L. Goldstein ${ }^{\mathrm{c}}$ \\ aVanderbilt University School of Medicine. Nashvill, Tennessee, USA \\ bUniversity of Alabama at Birmingham, Birmingham, Alabama, USA \\ 'Cincinnati Children's Hospital Medical Center, Cincinnati, Ohio, USA
}

\begin{abstract}
Renal replacement therapy (RRT) is used in a wide variety of pediatric populations. In this article, we will review the advantages and disadvantages of the different RRT modalities and the technical aspects of providing pediatric RRT. In addition, we will review the use of RRT with extracorporeal membrane oxygenation, the use of continuous RRT in the critically ill child with acute kidney injury and fluid overload, and the use of RRT for the removal of toxins and treatment of inborn errors of metabolism.
\end{abstract}

\section{Keywords}

Pediatric renal replacement therapy; Peritoneal dialysis; Hemodialysis; Continuous renal replacement therapy; Extracorporeal membrane oxygenation

\section{Introduction}

The first reports of pediatric renal replacement therapy (RRT) occurred in 1961 with the use of peritoneal dialysis (PD) for infants and children [1]. PD remains the primary form of long-term RRT for children with end-stage renal disease [2, 3], and continues to be used to support children with acute kidney injury (AKI). With improved technology, there has been an increased emphasis on continuous renal replacement therapy (CRRT) in critically ill neonates and children. In this article, we will explore the indications for providing RRT to children, review current RRT modalities used in children and the technical aspects that are unique to providing RRT in children.

\section{RRT and Pediatric Populations}

RRT for critically ill children can be divided into renal and nonrenal indications, such as inborn errors of metabolism/ hyperammonemia, drug toxicity, and tumor lysis syndrome. The Prospective Pediatric Continuous Renal Replacement Therapy (ppCRRT) Registry is a multicenter collaborative registry that did not assign clinical decision making, but

*Correspondence: Brian C. Bridges, MD, FAAP, Division of Pediatric Critical Care - Vanderbilt University School of Medicine, ECMO Medical Director, Doctor's Office Tower, Room 5120, 2200 Children's Way, Nashville, TN 37232-9075, USA, Telephone: +1-615-936-3968, brian.c.bridges@ vanderbilt.edu. 
prospectively collected and analyzed data from children who received CRRT between 2001 and 2005 in 13 United States centers. A report from the ppCRRT Registry revealed that 294/344 (86\%) CRRTs were performed for fluid overload, AKI, electrolyte abnormalities, or a combination of these [4]. The other 50 (15\%) CRRT procedures were for nonrenal indications, of which 21 (42\%) were for inborn errors of metabolism, 18 (36\%) were for drug toxicity, and $11(22 \%)$ were for tumor lysis syndrome [5].

Over the last few decades, the epidemiology of pediatric AKI has changed such that primary renal diseases (such as hemolytic uremic syndrome) are no longer the most common cause of AKI. Instead, the majority of cases of AKI are associated with multiorgan dysfunction syndrome, nephrotoxic medications, and septic shock. Many of these children have cardiac, oncologic, hepatic, or pulmonary chronic diseases [6].

In neonates, single-center prospective studies in very low- birth-weight infants [7], infants who undergo cardiopulmonary bypass $[8,9]$, infants requiring extracorporeal membrane oxygenation (ECMO) [10,11], and in infants with perinatal birth asphyxia [12] suggest that neonatal AKI is common and associated with poor outcomes [13, 14].

The incidence and outcomes of pediatric AKI depend on the patient population described. A study of 3,396 admissions to a tertiary pediatric intensive care unit (PICU) revealed that $5.7 \%$ of patients had some degree of AKI at the time of admission and $10 \%$ developed AKI during the course of the PICU stay. For these children, any AKI on admission and any development or worsening of AKI were independently associated with mortality, with the odds of mortality increasing with each grade increase in RIFLE (Risk, Injury, Failure, Loss, and End-Stage Kidney Disease) score ( $<$ 0.01). Children with AKI at the time of admission had a length of stay twice that of those with normal renal function, and those who developed AKI during the ICU course had a fourfold increase in the ICU length of stay [15]. Studies which evaluate children in the PICU who are intubated and on medications for blood pressure support suggest that $80 \%$ of these infants develop AKI, and those with AKI have worse clinical outcomes [13].

There have been several studies showing the relationship between fluid overload and mortality in critically ill children. Table 1 outlines 7 pediatric studies that demonstrate that 10-20\% fluid overload at the time of CRRT initiation was associated with increased mortality independent of severity of illness and other clinical factors. These studies include more than 800 patients and suggest that fluid provision during the ICU stay, and early initiation of CRRT in critically ill children with AKI and fluid overload may improve outcomes.

There is considerable mortality among critically ill children who require CRRT. A prospective, observational trial of 174 critically ill children between 1 month and 22 years of age requiring CRRT revealed an overall mortality of 35.6\%. Multiple organ failure and hemodynamic disturbances were the primary cause of death in these patients. Mortality was highest in children less than 12 months of age $(44.7 \%$; $\mathrm{p}=0.037)$ and in patients with a diagnosis of sepsis $(44.1 \% ; \mathrm{p}=0.001)$. Hemodynamic instability at the time of starting 
CRRT (hypotension or need for a high-dose epinephrine infusion) and the presence of multiple organ failure were all associated with an increased risk of mortality [16] .

A report of 344 PICU patients from the ppCRRT Registry Group revealed an overall mortality of 58\% for patients requiring CRRT. Survival was lowest when CRRT was started for liver disease/transplant (31\%), pulmonary disease/transplant (45\%), bone marrow transplant (45\%), or combined fluid overload and electrolyte imbalance (51\%). The highest survival was seen in patients treated with CRRT for drug intoxication (100\%), renal disease $(84 \%)$, tumor lysis syndrome (83\%), and inborn errors of metabolism (73\%). Overall survival was better for children weighing more than $10 \mathrm{~kg}(63 \mathrm{vs.} 43 \% ; \mathrm{p}=0.001)$ and for those older than 1 year of age (62 vs. $44 \% ; \mathrm{p}=0.007)$ [4].

\section{Pediatric RRT Modalities}

\section{Peritoneal Dialysis}

PD is the overwhelming choice of RRT for young children requiring long-term dialysis. In the chronic setting, PD is usually performed with an automated cycler, typically with 8-12 short nighttime cycles and a small residual dwell during the day [17]. In the ICU setting, PD is usually performed with manual setup using continuous hourly cycles of $10-20 \mathrm{ml} / \mathrm{kg}$ per dwell. PD can be used in the acute setting. For example, PD has been shown to be a safe and effective form of RRT after repair of congenital heart disease [18-23]. Immediate use of PD has been shown to reduce fluid overload in children at high risk of AKI after cardiopulmonary bypass [24, 25]. PD in the ICU has several advantages over intermittent hemodialysis (IHD) and CRRT. First, no anticoagulation is required [26]. Second, it is the least expensive form of RRT, which is critical in parts of the world with limited access to technology and resources [27]. Third, a peritoneal catheter access may be easier to establish than reliable vascular access. Finally, as opposed to IHD, PD provides continuous ultrafiltration with less potential for hemodynamic instability secondary to sudden fluid shifts.

In addition, there are several other advantages to $\mathrm{PD}$ in children who may require long-term RRT. Because a blood prime is needed when the extracorporeal blood circuit is $110 \%$, PD can provide RRT without exposure to blood products. Avoidance of blood exposure has significant implications on future transplant. PD provides gradual expansion of the abdominal cavity to allow for future renal transplantation [3]. Children who require longterm RRT may grow better when treated with PD rather than IHD [28].

PD does have several limitations. While PD can correct hyperkalemia and uremia, IHD and CRRT provide more efficient and expeditious small solute clearance and greater clearance of higher-molecular-weight solutes. Thus, PD does not provide the urgent clearance needed for acute intoxications, tumor lysis syndrome, symptomatic hyperkalemia, or hyperammonemia $[3,29]$. PD may not be feasible in patients with congenital anomalies such as gastroschisis, omphalocele, or adhesions from previous abdominal surgeries. By far, the biggest risk of PD is the development of peritonitis. Immunoglobulins can be lost with PD, thus increasing the risk of peritonitis and other infections [30]. Peritonitis can lead to increased dialysate protein 
loss, compromised nutrition, loss of ultrafiltration production, and damage to the peritoneal membrane [31].

\section{Intermittent Hemodialysis}

IHD produces solute clearance via diffusion across a semipermeable membrane into a dialysate fluid. With IHD, high blood flow and dialysate flow rates make it the form of RRT with the most rapid solute clearance and removal of extracellular fluid volume [32].

With IHD, the dialysate composition can easily be adjusted to treat electrolyte abnormalities [33]. As opposed to CRRT, IHD can provide substantial clearance in several hours, which allows the patient freedom from a machine for most of the day. This can be very important as children rehabilitate from acute illness. IHD is technically challenging to provide, and it requires skilled personnel in a specialized medical center or hemodialysis clinic. IHD also depends on reliable vascular access to provide adequate blood flows. In addition, the rapid volume shifts that accompany IHD may not be adequately tolerated in small children or in critically ill children with hemodynamic instability. With IHD, there is a risk of disequilibrium syndrome, in which rapid removal of urea causes an osmotic gradient between plasma and the brain resulting in cerebral edema and potential death [34]. Although some pediatric centers use sustained low-efficiency dialysis [35], very little has been published on its use in pediatric patients.

\section{Continuous Renal Replacement Therapy}

Recently, AKI and fluid overload during critical illness has gained increased recognition, and CRRT has become an increasingly popular means of support in the PICU. CRRT is being used successfully in even the most hemodynamically unstable patients, including neonates and patients requiring ECMO. CRRT provides several advantages for the support of critically ill patients as fluid goals can be adjusted based on the patient's status. Another advantage is that with a continuous modality, there is no need for fluid restriction, which allows for the provision of nutrition, blood products, and medications without worsening fluid overload.

CRRT can result in significant clearance of amino acids, and patients requiring CRRT typically have an increased protein requirement. One study found an 11-12\% loss of dietary amino acids and a negative nitrogen balance in pediatric patients receiving CRRT despite the delivery of parenteral nutrition containing $1.5 \mathrm{~g} / \mathrm{kg} /$ day of protein and caloric intake of 20 $30 \%$ above resting energy expenditure [36].Thus, current recommendations are to add an additional $1-1.5 \mathrm{~g} / \mathrm{kg} /$ day or more to usual protein needs to account for losses during CRRT.

There are several barriers to the use of CRRT in children. Due to technical and personnel considerations, CRRT is only offered to children at tertiary pediatric hospitals and is more expensive than other forms of dialysis. CRRT requires personnel who are trained in the initiation of the therapy as well as the continued maintenance of the machine. CRRT requires reliable vascular access, which can be difficult to obtain in neonates and infants.

Another challenge of CRRT is that it requires anticoagulation. Regional anticoagulation is typically done with citrate and a calcium infusion to the patient. Ideally, the calcium infusion 
requires reliable central vascular access either separate from the catheter used for CRRT or it can be infused into the access for CRRT if a third lumen is available. However, if no separate line is available, calcium can be infused in the CRRT venous return catheter as long as the blood pump flow rate is higher than $50 \mathrm{ml} / \mathrm{min}$. If systemic anticoagulation is used, there is a risk of life-threatening bleeding [37].

CRRT can be configured to provide clearance via convection, diffusion, or a combination of convection and diffusion. CRRT modalities performed using convection include slow continuous ultrafiltration and continuous veno-venous hemofiltration (CVVH). Slow continuous ultrafiltration simply provides ultrafiltrate production with convection and no filter replacement fluid, which confers a considerable risk of electrolyte abnormalities. Continuous veno-venous hemodialysis (CVVHD) provides CRRT using diffusion, and continuous veno-venous hemodiafiltration (CVVHDF) uses a combination of convection and diffusion.

\section{Technical Considerations of Pediatric RRT}

\section{Access}

For IHD and CRRT, vascular access that allows adequate blood flow can be a major challenge in neonates and infants. Table 2 shows the recommended vascular access sizes for children [38]. The ppCRRT report on vascular access in pediatric CRRT patients found that functional survival of the CRRT circuit increased significantly when using a larger-diameter catheter, when the catheter was placed in the internal jugular vein versus the subclavian or femoral vein, and with the use of CVVHD versus CVVH or CVVHDF. In this study, 48hour circuit survival was 76 versus $26 \%$ for CRRT using 8 -french versus 7 -french access, and it was less than $10 \mathrm{~h}$ for dual 5 -french catheters. None of the 5-french catheters lasted longer than $20 \mathrm{~h}$, independent of patient size. It is unclear why the use of CVVHD was associated with longer circuit survival than CVVH or CVVHDF [39], but it may be due to the increased filtration fraction and transmembrane pressures associated with convective modalities.

Neonates can accommodate 7-french catheter placement in the internal jugular vein for CRRT, and this has been reported using a cut-down technique similar to that used for ECMO cannulation [40]. With the use of bedside ultrasound, a skilled provider can percutaneously place an internal jugular catheter for RRT even in small children. The placement of catheters for IHD or CRRT can result in vascular stenosis, thrombosis, air emboli, or hemorrhage. Depending on the location or degree of difficulty involved in placing vascular catheters, future vascular access for long-term IHD may be compromised. For any child at risk of long-term RRT, subclavian vein catheter placement should be avoided if possible, due to the high stenosis rate at the site of puncture, making future attempts of forming an arteriovenous fistula difficult [41].

As opposed to access for long-term IHD, the vascular access for pediatric RRT in the ICU is often placed percutaneously, without a cuff, and at the bedside. If use of a catheter is anticipated to last more than a few weeks, or in very small infants, insertion of a cuffed catheter in the operating room by a pediatric surgeon may decrease the risk of infection 
associated with long-term use of catheters. In the absence of signs of infection, there is no evidence for routinely changing out these catheters. It is recommended that these catheters be removed as soon as they are no longer needed or to replace them with more permanent access if long-term RRT is necessary. When catheters are not in use, they are routinely locked with high-concentration heparin solutions. Care should be taken such that highconcentration solutions are not used in small infants, and in those at high risk for bleeding.

\section{Blood Prime}

The initiation of IHD or CRRT in neonates and small children presents a unique challenge as a substantial portion of the patient's blood volume is pumped through the extracorporeal circuit. The initiation process is the most critical and requires special attention to detail, clear protocols, and skilled nursing. The blood volume of a child is approximately $80 \mathrm{ml} / \mathrm{kg}$ (for example a 5-kg child has a blood volume of $400 \mathrm{ml}$ ). The smallest IHD extracorporeal volume (ECV) is approximately $45 \mathrm{ml}$ (about $11 \%$ of the ECV of a $5-\mathrm{kg}$ child), while the smallest ECVs for CRRT circuits are about $100 \mathrm{ml}$ (about $25 \%$ of the ECV of a 5-kg child). When using an extracorporeal circuit that is more than 10-15\% of the patient's blood volume, blood priming of the circuit is needed to prevent hypotension and anemia [38].

A unit of packed red blood cells (PRBCs) has an approximate $\mathrm{pH}$ of 6.8, ionized calcium of $0.3 \mathrm{mEq} / \mathrm{dl}$, hematocrit of $70 \%$, and high serum potassium levels. Thus, maneuvers to make a more physiologic volume are necessary when using blood primes. When CRRT is used for a neonate or small child, it is advisable to correct the $\mathrm{pH}$ of the PRBCs and achieve a normal patient ionized calcium level prior to starting therapy when possible [42]. To correct the $\mathrm{pH}$ of the PRBCs, most centers mix an equal volume of bicarbonate solution and PRBCs using a Y-connector, drawing the blood and bicarbonate into the circuit simultaneously. To account for the low ionized calcium level of the PRBCs, some give intravenous calcium to the return line, while others infuse it directly to the patient.

There is center variation on the methods of IHD and CRRT initiation. For example, some institutions will prime the circuit with the banked blood, while others infuse banked blood to the patient and simultaneously prime the circuit with the child's blood (blood transfusion and CRRT machine blood flow run at the same rate). Figure 1 shows a detailed step-by-step protocol which mixes PRBCs and sodium bicarbonate using a Y-connector, transfuses blood to the patient while simultaneously priming the circuit with the patient's blood in a circuit with an estimated ECV of $100 \mathrm{ml}$.

\section{Anticoagulation}

Both IHD and CRRT are typically performed using anticoagulation. In children, the blood flow rates are often lower and the vascular access is smaller, both of which increase the risk of clotting. Systemic anticoagulation of the patient and circuit is typically achieved with heparin. When systemic anticoagulation with heparin is used with CRRT, serial activated clotting times are typically followed to adjust the heparin infusion. Systemic anticoagulation remains the standard for IHD in children, although citrate anticoagulation for IHD has been studied in children [43]. Regional anticoagulation is typically done with citrate infusion to the circuit and a calcium infusion to the patient. In children with coagulopathy or who are at 
increased risk of hemorrhage, regional anticoagulation of the extracorporeal circuit is preferred. With this method, a citrate solution is delivered before filtering and binds calcium in the extracorporeal blood of the circuit and prevents clotting. The patient receives an intravenous calcium infusion that binds the systemic citrate and prevents hypocalcemia. Some of the citrate is cleared by the hemofilter [44], and the citrate that reaches the systemic circulation is metabolized by the liver and muscle to bicarbonate. Around the time of CRRT initiation, circuit and patient ionized calcium levels are measured frequently initially, and once stable doses are documented, they are measured every $6-8 \mathrm{~h} \mathrm{[37].} \mathrm{The} \mathrm{citrate} \mathrm{rate} \mathrm{is}$ adjusted to keep circuit ionized calcium levels between 0.25 and $0.4 \mathrm{mg} / \mathrm{dl}$, while the systemic calcium infusion rate is adjusted to keep the patient calcium level between 1.1 and $1.3 \mathrm{mg} / \mathrm{dl}$.

The risks of regional anticoagulation with citrate include metabolic alkalosis and hypocalcemic citrate toxicity. Citrate accumulation occurs when the patient fails to clear the citrate adequately in the setting of liver failure, decreased tissue perfusion, and in premature infants who have immature hepatic citrate metabolism. In this situation, the patient ionized calcium drops, but the patient total calcium, including that which is bound to citrate, increases. This occurs as a calcium infusion is given to the patient, but the excess citrate continues to bind free calcium. This complication is typically remedied by temporarily stopping the citrate infusion and restarting the infusion at a lower rate, and/or by increasing the replacement/ dialysis fluid clearance rates. The target circuit calcium and patient calcium levels may need to be adjusted to avoid citrate toxicity. The circuit ionized calcium is maintained by adjusting the citrate infusion, and the patient's systemic ionized calcium concentration is maintained by adjusting the calcium chloride infusion [38].

Analysis of the ppCRRT Registry showed no difference in mean circuit survival whether heparin anticoagulation $(42.1 \pm 27.1 \mathrm{~h})$ or citrate was used $(44.7 \pm 35.9 \mathrm{~h})$. However, circuit survival was significantly lower in circuits in which no anticoagulation was used (27.2 $\pm 21.5 \mathrm{~h}, \mathrm{p}<0.005$ ). For those patients receiving systemic anticoagulation with heparin, the mean heparin administration rates were $13.7 \pm 7.1$ units $/ \mathrm{kg} / \mathrm{h}$ (median 11.1, range 3.8-28.2). Despite this relatively modest heparin dose to keep activated clotting times between 180 and $220 \mathrm{~s}$, patients who received heparin anticoagulation had life-threatening bleeding complications that were not present in the group treated with citrate anticoagulation [37].

\section{Technical Considerations for RRT with Other Extracorporeal Technologies}

The use of RRT with ECMO has become commonplace. A recent international survey of 65 ECMO centers revealed that the indications to begin RRT for ECMO patients were fluid overload (43\%), AKI (35\%), fluid overload prevention (16\%), and electrolyte abnormalities (4\%). Only $23 \%$ did not use RRT for patients on ECMO [45] .

For the critically ill child, ECMO provides a platform to which RRT can be added into the extracorporeal circuit. With the heparinized ECMO circuit, no additional vascular access is necessary to add RRT and no additional anticoagulation is needed. Any modality of RRT could be provided on ECMO. However, due to the hemodynamic instability that is often present in the child on ECMO, CRRT is the modality that is most often used. CRRT can be provided to the child on ECMO via two different methods. A hemofilter can be placed in- 
line with the ECMO circuit ( fig. 2). With this method, ultrafiltrate production can be controlled with the use of an intravenous pump. However, this method should be used with caution, because when using intravenous infusion pumps for regulating ultrafiltrate on ECMO, there has been a reported maximal error in fluid management of up to $34 \mathrm{ml} / \mathrm{h}$ or approximately $840 \mathrm{ml} /$ day [46]. Ultrafiltrate production should be monitored either by weighing or measuring the actual volume removed. Ideally, when using a fluid should be used. While slow continuous ultrafiltration can be performed, there is a risk of serious electrolyte abnormalities with this method.

The second method involves connecting a commercially available CRRT device into the ECMO circuit (fig. 3). With either method, the return from the hemofilter or CRRT device should be placed before the ECMO oxygenator, so that any clot or air will be trapped instead of being sent to the patient. The access pressure alarms inherent to commercially available CRRT have set limits based on the individual CRRT device. Typically, the default access pressure alarms are negative. However, when operated in series with ECMO, the positive pressure at the entry point of the CRRT device will create pressures close to zero or positive. These pressures can lie outside the default limits of the device and thus, the alarm settings may have to be changed when using CRRT on ECMO. If these default access pressures cannot be changed, flow restrictors can be placed on the tubing to keep the pressures within the alarm limits.

\section{RRT for "Nonrenal" Indications}

\section{Intoxications}

The American Association of Poison Control Centers reported that in 2010 there were over 1.5 million exposures to toxic substances in children less than 20 years of age, and that children accounted for more than $63 \%$ of all exposures. Of those children less than 20 years of age, $123 \mathrm{had}$ an exposure treated with hemodialysis and 14 required ECMO, hemoperfusion, or 'other' extracorporeal procedure [47]. RRT has been used for a wide variety of intoxications, including vancomycin, aminoglycosides, lithium, theophylline, carbamazepine, valproic acid, aspirin, metformin, and methotrexate [48]. Large-molecularweight toxins and toxins that are highly protein bound are less efficiently removed by RRT. However, even intoxications that are highly protein-bound can be removed through the use of high-flux or high-efficiency hemodialysis membranes. Hemodialysis with high-flux or high-efficiency membranes is considered a first-line treatment of intoxications in patients that are hemodynamically stable. Hemodialysis with high-flux or high efficiency membranes followed by convective clearance with CRRT can be used for intoxications with large volumes of distribution or if an extended-release medication was ingested. In cases of an overdose of extended-release lithium, the use of hemodialysis followed by subsequent hemofiltration will allow for ongoing elimination of lithium and prevention of the rebound effect $[49,50]$. In the patient with hemodynamic instability, CRRT is the modality of choice to clear exogenous intoxications. In addition, single-pass albumin dialysis and molecular adsorbent recirculation system can be performed to remove toxins which are highly proteinbound and do not have a very large volume of distribution such as carbamazepine, methotrexate, phenytoin, and acetaminophen [51-56]. As opposed to AKI, patients receiving 
dialysis for the treatment of an acute intoxication typically require a dialysis fluid or replacement fluid with therapeutic concentrations of phosphorus and potassium to avoid electrolyte abnormalities [48]. When CRRT is used for intoxications, effluent rates higher than those typically used for AKI should be used to enhance clearance.

\section{Hyperammonemia}

Neonatal hyperammonemia may be caused by defects in one of the enzymes of the urea cycle, by organic acidurias, or by defects of fatty acid oxidation. A routine workup for hyperammonemia should be undertaken in the neonate with a plasma ammonia level greater than $150 \mu \mathrm{mol} / \mathrm{l}$. The presence of acidosis, increased anion gap, ketonuria, and abnormal blood cell counts is suggestive of an organic aciduria. Alkalosis with low blood urea nitrogen is typical of urea cycle defects. Defects in fatty acid oxidation are usually accompanied by hypoketotic hypoglycemia [57, 58]. Management of the infant with hyperammonemia includes:

- $\quad$ rehydration as many of these infants will be severely dehydrated

- $\quad$ performing diagnostic analysis from the serum and urine of amino acids and organic acids to determine the underlying cause in consultation with metabolic experts

- decreasing toxin production and preventing catabolism by providing adequate glucose by assigning a high-calorie, protein-free diet (can be achieved with glucose 8 insulin)

- initiation of a metabolic cocktail of arginine, carnitine, hydroxycobalamin, and biotin [58]

- removal of accumulating metabolites.

Both IHD and CRRT have been used to treat hyperammonemia in children with inborn errors of metabolism. RRT should be initiated as soon as possible in patients with excessive hyperammonemia as the duration of hyperammonemia is directly associated with morbidity and mortality [59]. In those with mild hyperammonemia, a brief trial of hydration and medical therapy can be instituted before initiation of CRRT.

Small molecules such as ammonium are cleared rapidly by diffusive or convective transport. To bring down high ammonia levels, IHD or very-high-volume CVVHD [60] are preferred over standard CRRT or PD [58]. In one case series, 13 neonates with hyperammonemia received RRT with only $\mathrm{CVVH}$, and the median ammonia level was decreased by $87 \%$ (mean $81 \pm 3.5$ ) at $24 \mathrm{~h}$. Eleven of the 13 patients $(85 \%)$ achieved an ammonia level of less than $200 \mu \mathrm{mol} / \mathrm{l}$ in $24 \mathrm{~h}$ or less [61]. Once rapid reduction of ammonia with IHD or highvolume CRRT has been performed, conventional CRRT can be instituted to maintain normal ammonia levels while metabolic control with diet and medications is achieved.

\section{Future of Pediatric RRT}

Numerous systematic issues need to be addressed to improve outcomes in children with AKI and intoxications/ inborn errors of metabolism who require RRT. Children are ideal to study 
how interventions affect outcomes as the underlying cause of AKI is usually known, and pre-existing conditions (such as diabetes, vascular disease, and chronic kidney disease) are not commonly present in children with AKI. Collaboration between multiple pediatric centers and funding from industry, associations, and government institutions will be essential to determine the optimal way to prescribe RRT for children.

- $\quad$ Currently there are minimal evidence-based guidelines for dialysis prescription and current therapies vary based on individual/center experience and data from adult studies. Prospective databases to answer specific hypotheses about the best method to perform RRT are needed.

- $\quad$ The safety and efficacy of blood prime techniques that occur during IHD and CRRT need to be explored.

- $\quad$ Current dialysis machines are created for adults and adapted for children. New devices, catheters, machine software and filters designed for infants and small children receiving CRRT need to be developed and tested.

- Improvement in the early diagnosis of AKI or metabolic conditions, such as hyperammonemia, may allow for earlier or more effective CRRT provision.

- $\quad$ Any long-term clinical or survival benefits of CRRT provision versus use of PD or more conventional hemodialysis techniques in this population has yet to be determined.

- There is a great need for prospective intervention trials to determine the optimal timing of RRT using clinical biomarkers (such as fluid overload) and novel serum and urine biomarkers.

- There is a great deal of variation on the use of RRT in conjunction with the other extracorporeal therapies, such as ECMO and plasma exchange. A standardized way of providing these therapies should be developed.

- $\quad$ The use of RRT to provide clearance of inflammatory cytokines in children who undergo cardiopulmonary bypass and in children who have sepsis needs to be explored.

\section{References}

1. Chesney RW. The development of pediatric nephrology. Pediatr Res. 2002; 52:770-778. [PubMed: 12409527]

2. Schaefer F, Warady BA. Peritoneal dialysis in children with end-stage renal disease. Nat Rev Nephrol. 2011; 7:659-668. [PubMed: 21947118]

3. Zaritsky J, Warady BA. Peritoneal dialysis in infants and young children. Semin Nephrol. 2011; 31:213-224. [PubMed: 21439434]

4. Symons JM, Chua AN, Somers MJ, Baum MA, Bunchman TE, Benfield MR, Brophy PD, Blowey D, Fortenberry JD, Chand D, Flores FX, Hackbarth R, Alexander SR, Mahan J, McBryde KD, Goldstein SL. Demographic characteristics of pediatric continuous renal replacement therapy: a report of the prospective pediatric continuous renal replacement therapy registry. Clin J Am Soc Nephrol. 2007; 2:732-738. [PubMed: 17699489]

5. Fleming GM, Walters S, Goldstein SL, Alexander SR, Baum MA, Blowey DL, Bunchman TE, Chua AN, Fletcher SA, Flores FX, Fortenberry JD, Hackbarth R, McBryde K, Somers MJ, Symons JM, 
Brophy PD. Nonrenal indications for continuous renal replacement therapy: a report from the prospective pediatric continuous renal replacement therapy registry group. Pediatr Crit Care Med. 2012 E-pub ahead of print.

6. Goldstein SL. Pediatric acute renal failure: demographics and treatment. Contrib Nephrol. 2004; 144:284-290. [PubMed: 15264417]

7. Koralkar R, Ambalavanan N, Levitan EB, McGwin G, Goldstein S, Askenazi D. Acute kidney injury reduces survival in very low birth weight infant. Pediatr Res. 2011; 69:354-358. [PubMed: 21178824]

8. Blinder JJ, Goldstein SL, Lee VV, Baycroft A, Fraser CD, Nelson D, Jefferies JL. Congenital heart surgery in infants: effects of acute kidneyinjury on outcomes. J Thorac Cardiovasc Surg. 2012; 143:368-374. [PubMed: 21798562]

9. Krawczeski CD, Woo JG, Wang Y, Bennett MR, Ma Q, Devarajan P. Neutrophil gelatinaseassociated lipocalin concentrations predict development of acute kidney injury in neonates and children after cardiopulmonary bypass. J Pediatr. 2011; 158:1009-1015. e1. [PubMed: 21300375]

10. Askenazi DJ, Griffin R, McGwin G, Carlo W, Ambalavanan N. Acute kidney injury is independently associated with mortality in very low birthweight infants: a matched case-control analysis. Pediatr Nephrol. 2009; 24:991-997. [PubMed: 19238451]

11. Gadepalli SK, Selewski DT, Drongowski RA, Mychaliska GB. Acute kidney injury in congenital diaphragmatic hernia requiring extracorporeal life support: an insidious problem. J Pediatr Surg. 2011; 46:630-635. [PubMed: 21496529]

12. Kaur S, Jain S, Saha A, Chawla D, Parmar VR, Basu S, Kaur J. Evaluation of glomerular and tubular renal function in neonates with birth asphyxia. Ann Trop Paediatr. 2011; 31:129-134. [PubMed: 21575317]

13. Akcan-Arikan A, Zappitelli M, Loftis LL, Washburn KK, Jefferson LS, Goldstein SL. Modified rifle criteria in critically ill children with acute kidney injury. Kidney Int. 2007; 71:1028-1035. [PubMed: 17396113]

14. Zappitelli M, Parikh CR, Akcan-Arikan A, Washburn KK, Moffett BS, Goldstein SL. Ascertainment and epidemiology of acute kidney injury varies with definition interpretation. Clin J Am Soc Nephrol. 2008; 3:948-954. [PubMed: 18417742]

15. Schneider J, Khemani R, Grushkin C, Bart R. Serum creatinine as stratified in the RIFLE score for acute kidney injury is associated with mortality and length of stay for childrenin the pediatric intensive care unit. Crit Care Med. 2010; 38:933-939. [PubMed: 20124891]

16. Santiago MJ, Lopez-Herce J, Urbano J, Solana MJ, del Castillo J, Ballestero Y, Botran M, Bellon JM. Clinical course and mortality risk factors in critically ill children requiring continuous renal replacement therapy. Intensive Care Med. 2010; 36:843-849. [PubMed: 20237755]

17. Fleming GM. Renal replacement therapy review: past, present and future. Organogenesis. 2011; 7:2-12. [PubMed: 21289478]

18. Chien JC, Hwang BT, Weng ZC, Meng LC, Lee PC. Peritoneal dialysis in infants and children after open heart surgery. Pediatr Neonatol. 2009; 50:275-279. [PubMed: 20025141]

19. Pedersen KR, Hjortdal VE, Christensen S, Pedersen J, Hjortholm K, Larsen SH, Povlsen JV. Clinical outcome in children with acute renal failure treated with peritoneal dialysis after surgery for congenital heart disease. Kidney Int Suppl. 2008; 108:S81-S86.

20. Ricci Z, Morelli S, Vitale V, Di Chiara L, Cruz D, Picardo S. Management of fluid balance in continuous renal replacement therapy: technical evaluation in the pediatric setting. Int $\mathrm{J}$ Artif Organs. 2007; 30:896-901. [PubMed: 17992650]

21. Chan KL, Ip P, Chiu CS, Cheung YF. Peritoneal dialysis after surgery for congenital heart disease in infants and young children. Ann Thorac Surg. 2003; 76:1443-1449. [PubMed: 14602265]

22. Xinjin L, Jianping X, Xiangdong S, Xia C. Peritoneal dialysis after repair of congenital heart disease in children. Chin Med Sci J. 2003; 18:100-104. [PubMed: 12903792]

23. Dittrich S, Vogel M, Dahnert I, Haas NA, Alexi-Meskishvili V, Lange PE. Acute hemodynamic effects of post cardiotomy peritoneal dialysis in neonates and infants. Intensive Care Med. 2000; 26:101-104. [PubMed: 10663289] 
24. Sorof JM, Stromberg D, Brewer ED, Feltes TF, Fraser CD Jr. Early initiation of peritoneal dialysis after surgical repair of congenital heart disease. Pediatr Nephrol. 1999; 13:641-645. [PubMed: 10502118]

25. Bojan M, Gioanni S, Vouhe PR, Journois D, Pouard P. Early initiation of peritoneal dialysis in neonates and infants with acute kidney injury following cardiac surgery is associated with a significant decrease in mortality. Kidney Int. 2012 E-pub ahead of print.

26. Basu RK, Wheeler DS, Goldstein S, Doughty L. Acute renal replacement therapy in pediatrics. Int J Nephrol. 2011; 2011:785392. [PubMed: 21716713]

27. Nayak KS, Prabhu MV, Sinoj KA, Subhramanyam SV, Sridhar G. Peritoneal dialysis in developing countries. Contrib Nephrol. 2009; 163:270-277. [PubMed: 19494625]

28. Kaiser BA, Polinsky MS, Stover J, Morgenstern BZ, Baluarte HJ. Growth of children following the initiation of dialysis: a comparison of three dialysis modalities. Pediatr Nephrol. 1994; 8:733-738. [PubMed: 7696115]

29. Schaefer F, Straube E, Oh J, Mehls O, Mayatepek E. Dialysis in neonates with inborn errors of metabolism. Nephrol Dial Transplant. 1999; 14:910-918. [PubMed: 10328469]

30. Neu AM, Warady BA, Lederman HM, Furth SL, Fivush BA. Hypogammaglobulinemia in infants and young children maintained on peritoneal dialysis. Pediatric dialysis study consortium. Perit Dial Int. 1998; 18:440-443. [PubMed: 10505571]

31. Blake PG, Breborowicz A, Han DS, Joffe P, Korbet SM, Warady BA. Recommended peritoneal dialysis curriculum for nephrology trainees. The International Society for Peritoneal Dialysis (ISPD) Standards and Education Subcommittee. Perit Dial Int. 2000; 20:497-502. [PubMed: 11117240]

32. Quan A, Quigley R. Renal replacement therapy and acute renal failure. Curr Opin Pediatr. 2005; 17:205-209. [PubMed: 15800413]

33. Pazmino PA, Pazmino BP. Treatment of acute hypernatremia with hemodialysis. Am J Nephrol. 1993; 13:260-265. [PubMed: 8267023]

34. Patel N, Dalal P, Panesar M. Dialysis disequilibrium syndrome: a narrative review. Semin Dial. 2008; 21:493-498. [PubMed: 18764799]

35. Tolwani AJ, Wheeler TS, Wille KM. Sustained low-efficiency dialysis. Contrib Nephrol. 2007; 156:320-324. [PubMed: 17464142]

36. Maxvold NJ, Smoyer WE, Custer JR, Bunchman TE. Amino acid loss and nitrogen balance in critically ill children with acute renal failure: a prospective comparison between classic hemofiltration and hemofiltration with dialysis. Crit Care Med. 2000; 28:1161-1165. [PubMed: 10809299]

37. Brophy PD, Somers MJ, Baum MA, Symons JM, McAfee N, Fortenberry JD, Rogers K, Barnett J, Blowey D, Baker C, Bunchman TE, Goldstein SL. Multi-centre evaluation of anticoagulation in patients receiving continuous renal replacement therapy (CRRT). Nephrol Dial Transplant. 2005; 20:1416-1421. [PubMed: 15855212]

38. Goldstein SL. Advances in pediatric renal replacement therapy for acute kidney injury. Semin Dial. 2011; 24:187-191. [PubMed: 21517986]

39. Hackbarth R, Bunchman TE, Chua AN, Somers MJ, Baum M, Symons JM, Brophy PD, Blowey D, Fortenberry JD, Chand D, Flores FX, Alexander SR, Mahan JD, McBryde KD, Benfield MR, Goldstein SL. The effect of vascular access location and size on circuit survival in pediatric continuous renal replacement therapy: a report from the PPCRRT registry. Int J Artif Organs. 2007; 30:1116-1121. [PubMed: 18203074]

40. Sutherland SM, Alexander SR. Continuous renal replacement therapy in children. Pediatr Nephrol. 2012 E-pub ahead of print.

41. Walters S, Porter C, Brophy PD. Dialysis and pediatric acute kidney injury: choice of renal support modality. Pediatr Nephrol. 2009; 24:37-48. [PubMed: 18483748]

42. Hackbarth RM, Eding D, Gianoli Smith C, Koch A, Sanfilippo DJ, Bunchman TE. Zero balance ultrafiltration (Z-BUF) in blood-primed CRRT circuits achieves electrolyte and acid-base homeostasis prior to patient connection. Pediatr Nephrol. 2005; 20:1328-1333. [PubMed: 15947984] 
43. Kreuzer M, Bonzel KE, Buscher R, Offner G, Ehrich JH, Pape L. Regional citrate anticoagulation is safe in intermittent high-flux haemodialysis treatment of children and adolescents with an increased risk of bleeding. Nephrol Dial Transplant. 2010; 25:3337-3342. [PubMed: 20466660]

44. Chadha V, Garg U, Warady BA, Alon US. Citrate clearance in children receiving continuous venovenous renal replacement therapy. Pediatr Nephrol. 2002; 17:819-824. [PubMed: 12376810]

45. Fleming, GM., Askenazi, DJ., Zappitelli, M., Paden, ML. RRT on ECMO study group: center practice survey results. 21st Annu Extracorp Life Support Organization Conf; St Petersburg. 2010.

46. Sucosky P, Dasi LP, Goldman SL, Paden ML, Fortenberry JD, Yoganathan AP. Assessment of current continuous hemofiltration systems and development of a novel accurate fluid management system for use in extracorporeal membrane oxygenation. J Med Device. 2008; 2:35002-35010.

47. Bronstein AC, Spyker DA, Cantilena LR Jr, Green JL, Rumack BH, Dart RC. 2010 annual report of the American Association of Poison Control Centers' National Poison Data System (NPDS): 28th annual report. Clin Toxicol (Phila). 2011; 49:910-941. [PubMed: 22165864]

48. Bunchman TE, Ferris ME. Management of toxic ingestions with the use of renal replacement therapy. Pediatr Nephrol. 2011; 26:535-541. [PubMed: 20938691]

49. van Bommel EF, Kalmeijer MD, Ponssen HH. Treatment of life-threatening lithium toxicity with high-volume continuous venovenous hemofiltration. Am J Nephrol. 2000; 20:408-411. [PubMed: 11093000]

50. Meyer RJ, Flynn JT, Brophy PD, Smoyer WE, Kershaw DB, Custer JR, Bunchman TE. Hemodialysis followed by continuous hemofiltration for treatment of lithium intoxication in children. Am J Kidney Dis. 2001; 37:1044-1047. [PubMed: 11325688]

51. Vilay AM, Mueller BA, Haines H, Alten JA, Askenazi DJ. Treatment of methotrexate intoxication with various modalities of continuous extracorporeal therapy and glucarpidase. Pharmacotherapy. 2010; 30:111. [PubMed: 20030480]

52. Askenazi DJ, Goldstein SL, Chang IF, Elenberg E, Feig DI. Management of a severe carbamazepine overdose using albumin-enhanced continuous venovenous hemodialysis. Pediatrics. 2004; 113:406-409. [PubMed: 14754959]

53. Karvellas CJ, Bagshaw SM, McDermid RC, Stollery DE, Bain VG, Gibney RT. A case control study of single-pass albumin dialysis for acetaminophen-induced acute liver failure. Blood Purif. 2009; 28:151-158. [PubMed: 19590182]

54. Sauer IM, Goetz M, Steffen I, Walter G, Kehr DC, Schwartlander R, Hwang YJ, Pascher A, Gerlach JC, Neuhaus P. In vitro comparison of the molecular adsorbent recirculation system (MARS) and single-pass albumin dialysis (SPAD). Hepatology. 2004; 39:1408-1414. [PubMed: 15122770]

55. Karvellas CJ, Bagshaw SM, McDermid RC, Stollery DE, Gibney RT. Acetaminophen-induced acute liver failure treated with single-pass albumin dialysis: report of a case. Int J Artif Organs. 2008; 31:450-455. [PubMed: 18609519]

56. Peszynski P, Klammt S, Peters E, Mitzner S, Stange J, Schmidt R. Albumin dialysis: single pass vs recirculation (MARS). Liver. 2002; 22(suppl 2):40-42. [PubMed: 12220302]

57. Summar M. Current strategies for the management of neonatal urea cycle disorders. J Pediatr. 2001; 138:S30-S39. [PubMed: 11148547]

58. Picca S, Bartuli A, Dionisi-Vici C. Medical management and dialysis therapy for the infant with an inborn error of metabolism. Semin Nephrol. 2008; 28:477-480. [PubMed: 18790367]

59. McBryde KD, Kershaw DB, Bunchman TE, Maxvold NJ, Mottes TA, Kudelka TL, Brophy PD. Renal replacement therapy in the treatment of confirmed or suspected inborn errors of metabolism. J Pediatr. 2006; 148:770-778. [PubMed: 16769384]

60. Lai YC, Huang HP, Tsai IJ, Tsau YK. Highvolume continuous venovenous hemofiltration as an effective therapy for acute management of inborn errors of metabolism in young children. Blood Purif. 2007; 25:303-308. [PubMed: 17643056]

61. Westrope C, Morris K, Burford D, Morrison G. Continuous hemofiltration in the control of neonatal hyperammonemia: a 10-year experience. Pediatr Nephrol. 2010; 25:1725-1730. [PubMed: 20495829]

62. Hoover NG, Heard M, Reid C, Wagoner S, Rogers K, Foland J, et al. Enhanced fluid management with continuous venovenous hemofiltration in pediatric respiratory failure patients receiving 
extracorporeal membrane oxygenation support. Intensive Care Med. 2008; 34:2241-2247. [PubMed: 18629472]

63. Santiago MJ, Sánchez A, López-Herce J, Pérez R, del Castillo J, Urbano J, Carrillo A. The use of continuous renal replacement therapy in series with extracorporeal membrane oxygenation. Kidney Int. 2009; 76:1289-1292. [PubMed: 19794394]

64. Selewski DT, Cornell TT, Lombel RM, Blatt NB, Han YY, Mottes T, Kommareddi M, Kershaw DB, Shanley TP, Heung M. Weight-based determination of fluid overload status and mortality in pediatric intensive care unit patients requiring continuous renal replacement therapy. Intensive Care Med. 2011; 37:1166-1173. [PubMed: 21533569]

65. Sutherland SM, Zappitelli M, Alexander SR, Chua AN, Brophy PD, Bunchman TE, Hackbarth R, Somers MJ, Baum M, Symons JM, Flores FX, Benfield M, Askenazi D, Chand D, Fortenberry JD, Mahan JD, McBryde K, Blowey D, Goldstein SL. Fluid overload and mortality in children receiving continuous renal replacement therapy: the prospective pediatric continuous renal replacement therapy registry. Am J Kidney Dis. 2010; 55:316-325. [PubMed: 20042260]

66. Hayes LW, Oster RA, Tofil NM, Tolwani AJ. Outcomes of critically ill children requiring continuous renal replacement therapy. J Crit Care. 2009; 24:394-400. [PubMed: 19327959]

67. Goldstein SL, Somers MJ, Baum MA, Symons JM, Brophy PD, Blowey D, Bunchman TE, Baker C, Mottes T, McAfee N, Barnett J, Morrison G, Rogers K, Fortenberry JD. Pediatric patients with multi-organ dysfunction syndrome receiving continuous renal replacement therapy. Kidney Int. 2005; 67:653-658. [PubMed: 15673313]

68. Gillespie RS, Seidel K, Symons JM. Effect of fluid overload and dose of replacement fluid on survival in hemofiltration. Pediatr Nephrol. 2004; 19:1394-1399. [PubMed: 15517417]

69. Foland JA, Fortenberry JD, Warshaw BL, Pettignano R, Merritt RK, Heard ML, Rogers K, Reid C, Tanner AJ, Easley KA. Fluid overload before continuous hemofiltration and survival in critically ill children: a retrospective analysis. Crit Care Med. 2004; 32:1771-1776. [PubMed: 15286557]

70. Goldstein SL, Currier H, Graf C, Cosio CC, Brewer ED, Sachdeva R. Outcome in children receiving continuous venovenous hemofiltration. Pediatrics. 2001; 107:1309-1312. [PubMed: $11389248]$ 


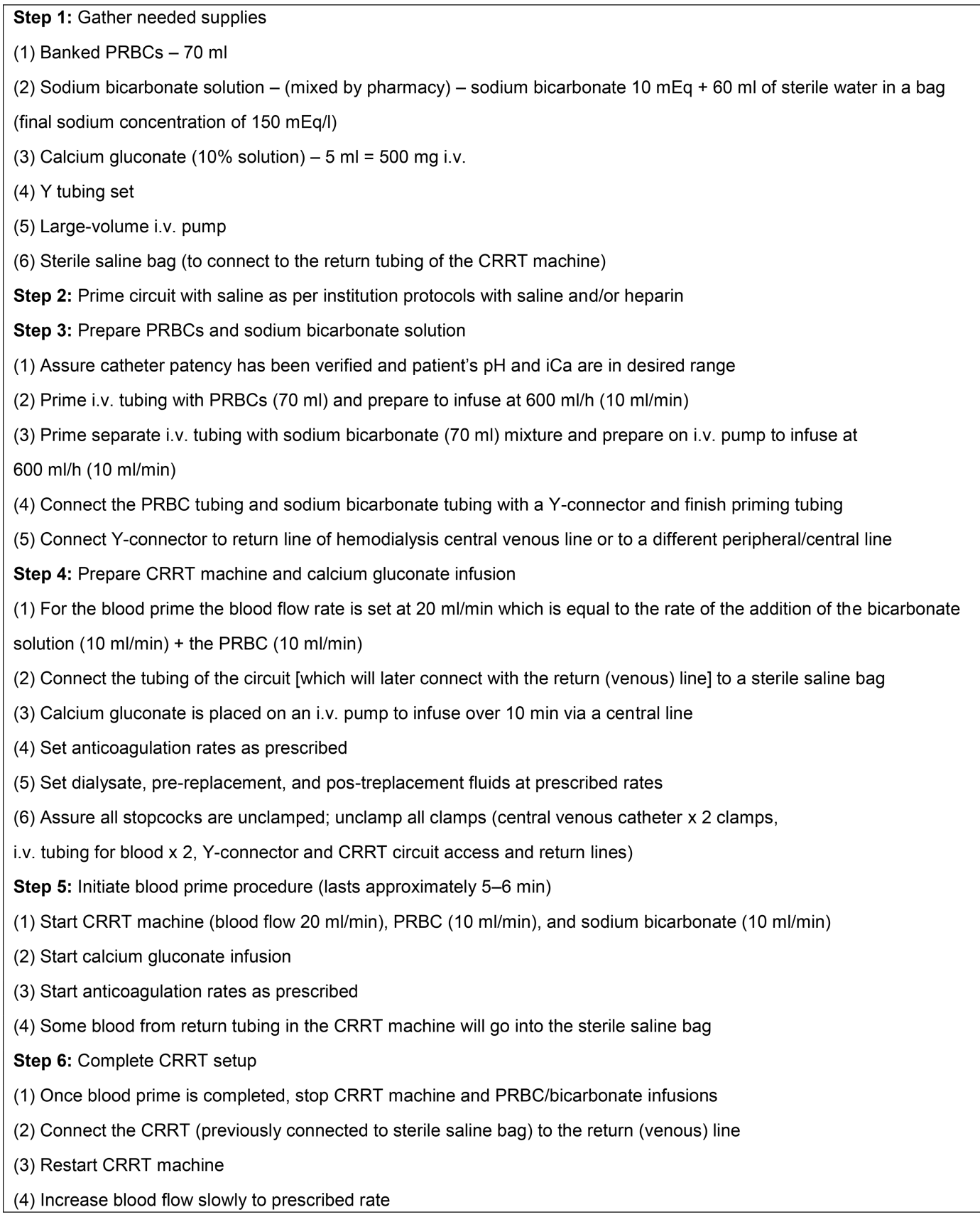

Figure 1. A detailed step-by-step protocol which mixes PRBCs and sodium bicarbonate using a Y-connector 


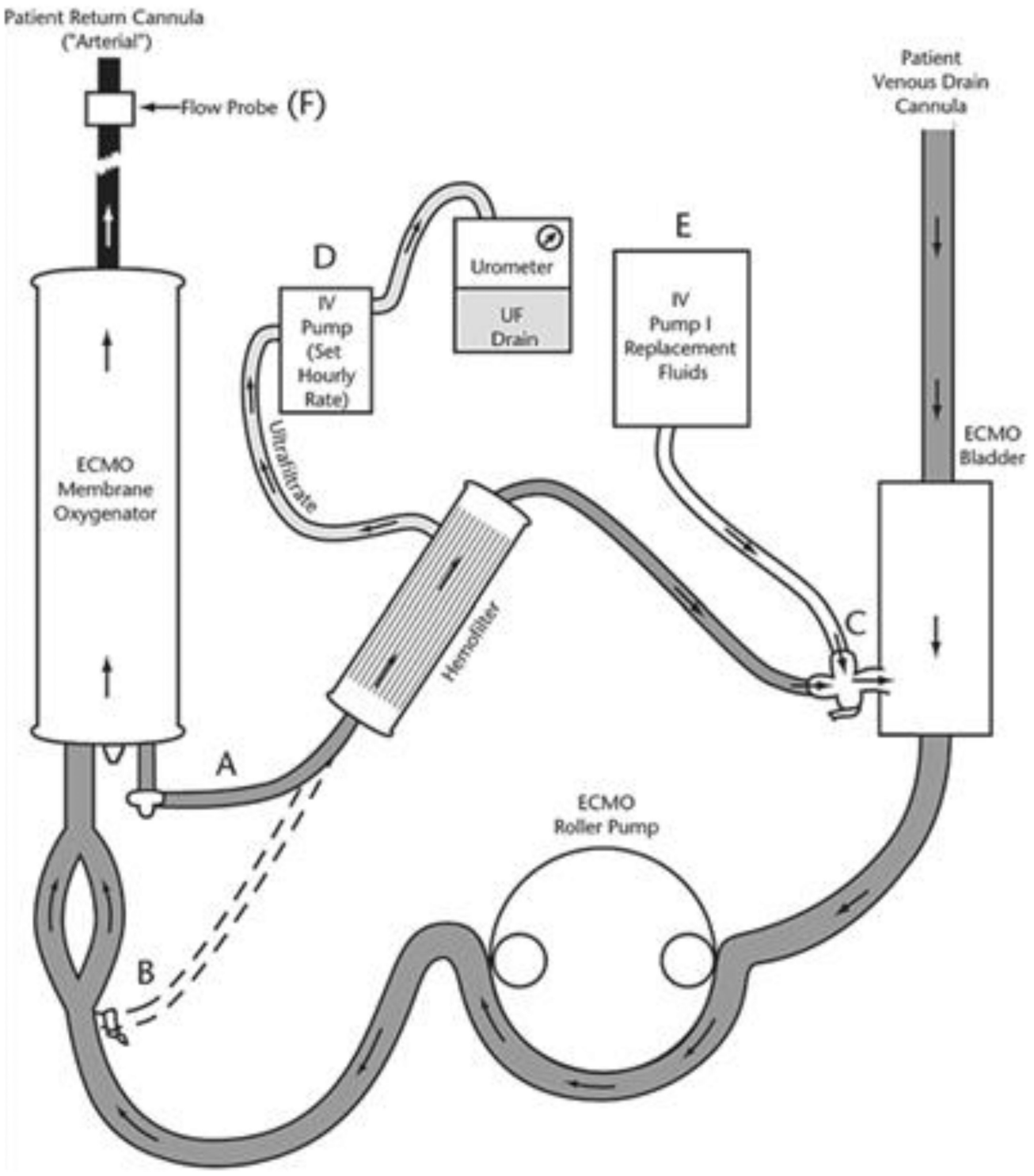

Figure 2. Schematic of an in-line hemofilter added to an ECMO circuit

Blood from the oxygenator is drained via a three-way stopcock and pigtail tubing (A) to the hemofilter. An alternate connection (B) can be made. Hemofilter circuit blood returns to circuit tubing (C) and a three-way stopcock to the venous bladder. Hemofilter ultrafiltrate is drained by an automated pump (D) and collected and measured with an urometer. An IV pump (E) can be used to supply filter replacement fluids. An electronic flow probe (F) measures actual postmembrane flow for calculation of hemofilter 'runoff'. Reprinted with permission from Hoover et al. [62]. 

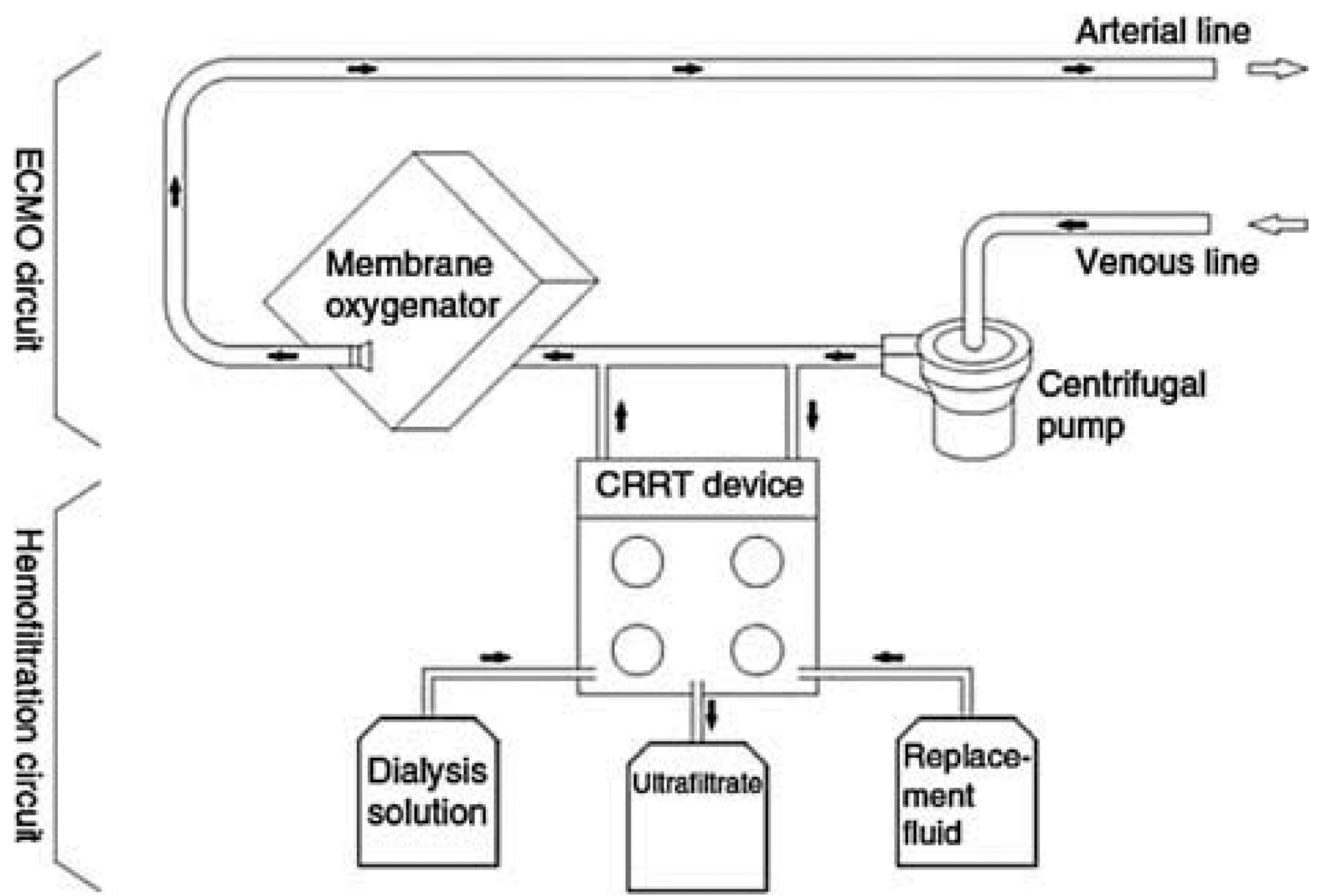

Figure 3. Schematic of the inclusion of a CRRT device into an ECMO circuit with a centrifugal pump

Reprinted with permission from Santiago et al. [63]. 
Table 1

Pediatric studies of fluid overload at the time of CRRT initiation and mortality

\begin{tabular}{l|l|l|l|}
\hline Author & Year & Patient number and design & Outcome \\
\hline Selewski et al. [64] & 2011 & $\begin{array}{l}113 \text { patients } \\
\text { Single-center, retrospective study }\end{array}$ & $\begin{array}{l}\text { Increased fluid overload associated with increased mortality, } \\
\text { independent of illness severity score and other clinical factors in } \\
\text { patients on ECMO and general pediatric critical care }\end{array}$ \\
\hline Sutherland et al. [65] & 2010 & $\begin{array}{l}297 \text { patients } \\
\text { Multicenter, prospective observational } \\
\text { study }\end{array}$ & $\begin{array}{l}\text { Fluid overload >20\% associated with increased mortality } \\
\text { independent of illness severity and other clinical factors }\end{array}$ \\
\hline Hayes et al. [66] & 2009 & $\begin{array}{l}76 \text { patients } \\
\text { Single-center, retrospective study }\end{array}$ & $\begin{array}{l}\text { Fluid overload >20\% associated with increased mortality } \\
\text { independent of illness severity and other clinical factors }\end{array}$ \\
\hline Goldstein et al. [67] & 2005 & $\begin{array}{l}\text { 116 patients } \\
\text { Multicenter, prospective observational } \\
\text { study }\end{array}$ & $\begin{array}{l}\text { Fluid overload >20\% associated with increased mortality } \\
\text { independent of illnesses severity and other clinical factors }\end{array}$ \\
\hline Gillespie et al. [68] & 2004 & $\begin{array}{l}77 \text { patients } \\
\text { Single-center, retrospective study }\end{array}$ & $\begin{array}{l}\text { Fluid overload >10\% was associated with increased mortality } \\
\text { independent of illness severity and other clinical factors }\end{array}$ \\
\hline Foland et al. [69] & 2004 & $\begin{array}{l}\text { 113 patients } \\
\text { Single-center, retrospective study }\end{array}$ & $\begin{array}{l}\text { Increased fluid overload associated with increased mortality } \\
\text { independent of illness severity score and other clinical factors }\end{array}$ \\
\hline Goldstein et al. [70] & 2001 & $\begin{array}{l}\text { 21 patients } \\
\text { Single-center study }\end{array}$ \\
\hline
\end{tabular}




\section{Table 2}

Catheter size for pediatric patients

\begin{tabular}{|l|l|l|}
\hline Patient size & Catheter size & Site of insertion \\
\hline Neonate & Dual-lumen 7.0 F & Internal jugular, femoral, or subclavian vein \\
\hline $3-6 \mathrm{~kg}$ & $\begin{array}{l}\text { Dual-lumen 7.0 F } \\
\text { Triple-lumen 7.0 F }\end{array}$ & Internal jugular, femoral, or subclavian vein \\
\hline 6-30 kg & Dual-lumen 8.0 F & Internal jugular, femoral, or subclavian vein \\
\hline$>15 \mathrm{~kg}$ & Dual-lumen 9.0 F & Internal jugular, femoral, or subclavian vein \\
\hline$>30 \mathrm{~kg}$ & Dual-lumen 10.0 F & Internal jugular, femoral, or subclavian vein \\
\hline
\end{tabular}

Table adapted from Goldstein [38] 